\title{
Quality Management IN THE AUtomotive INDUSTRY
}

\section{GoicoeChEA, I. \& FENOLLERA, M.}

Abstract: The automotive industry has always been an example in the field of Project Management and Leadership and, of course, as far as quality is concerned. An established methodology is followed from product development through production. The aim of this investigation is to set up a relationship between the different stages of the Product Realization Process (PRP) and the most suitable quality tools for each of them, so that it can be a support to the organizations interested when it comes to choosing the most effective tools depending on the quality strategy they adopt.

This paper: sets out the development of the main quality standards in the automotive sector; explains the most important characteristics of the PRP industry, obtaining a proposal of project management phases or stages; makes a classification of the main quality tools used based, on the one hand, on the extensive revision of specialized bibliography, and on the other hand, on the authors' experience; and finally uses a qualitative method of data collection in order to analyze the most adequate tools and to fit them in the different stages of the project.

Key words: automotive, project management, quality standards, quality tools, PRP
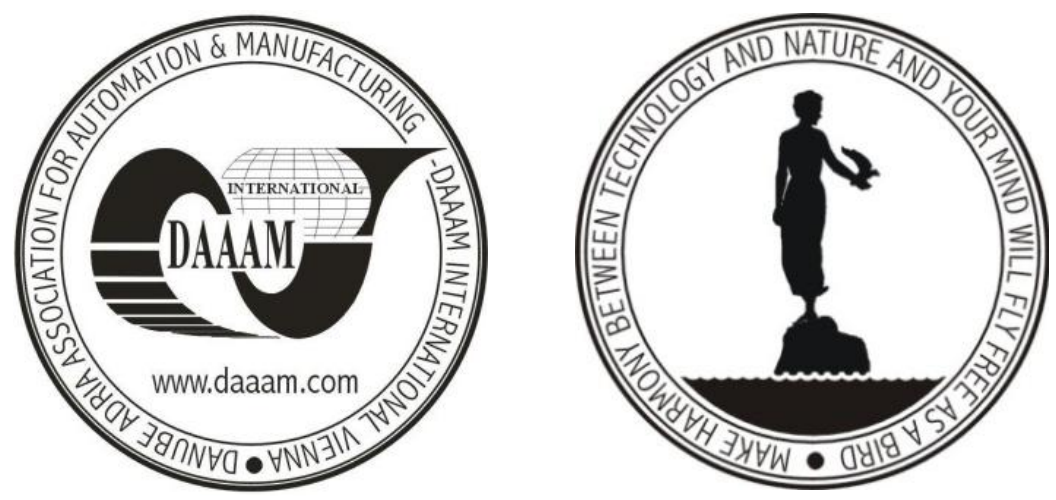

Authors' data: Univ. Prof. Dr. Eng. Goicoechea, I[tziar]; Univ. Prof. Eng. Fenollera, M[aria]; University of Vigo, School of Industrial Engineering. Campus Lagoas Marcosende s/n Vigo. Spain, igoicoechea@uvigo.es, mfenollera@uvigo.es

This Publication has to be referred as: Goicoechea, I[tziar] \& Fenollera, M[aria], (2012). Quality Management in the Automotive Industry, Chapter 51 in DAAAM International Scientific Book 2012, pp. 619-632, B. Katalinic (Ed.), Published by DAAAM International, ISBN 978-3-901509-86-5, ISSN 1726-9687, Vienna, Austria DOI:10.2507/daaam.scibook.2012.51 


\section{Introduction}

Increasing global competition over the past decade has forced automotive companies to improve quality and efficiency. Using the management tools that are relevant to the organization's needs has become a strategic issue for companies in today's competitive environment.

The project quality can be viewed in different ways. The factor of who assesses the quality, and what is the evaluation based on, is always decisive. However, the bottom line is always determined by customers`or skateholders`requirements (Nagyova \& Pacaiova, 2010). By choosing and applying the best management tools among too many management tools, companies can improve their performances and then increase customer satisfaction and gain market shares.

Management is characterized because of its global and comprehensive approach; it is and organizational strategy and management methodology that makes the members of an organization participate with the basic aim of continuously improving efficacy, efficiency and functionality. Automobile quality management system is based on the ISO/TS standard that focuses mainly on processes (Jiménez, 2008), and on the satisfaction of customers (intermediate or ultimate); and by which both employees and suppliers are involved (Fig. 1).

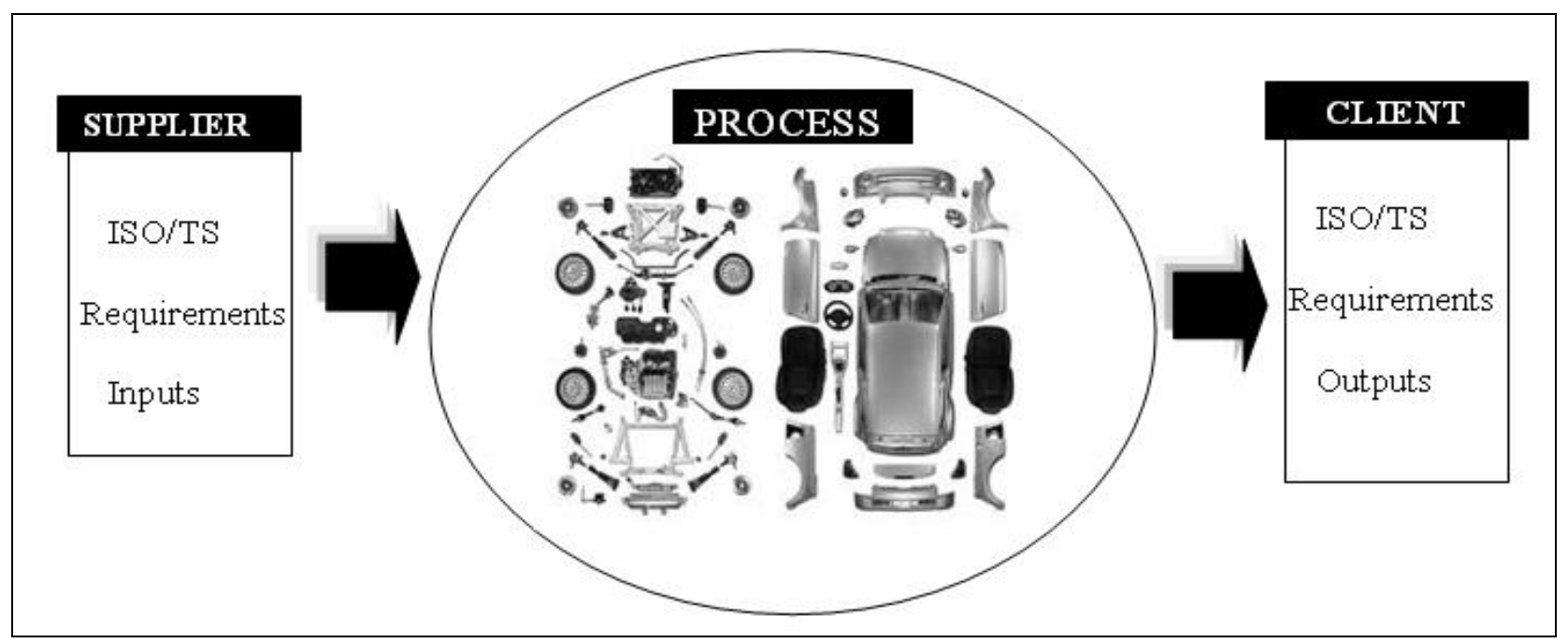

Fig. 1. ISO TS Process Approach

Quality management techniques and tools are instruments and methods that help to solve specific problems at different organization levels (Automotive Committee, 2004). There is a wealth of literature above all professional, on the specific tools related to quality management (Juran \& Gryna, 1998; Besterfield et al., 1999; Dale et al., 2007). They have been grouped according to different criteria and many classifications have been proposed, both in professional and academic literature; Greene (1993) describes up to 98 tools, grouped by the objectives set by companies. The entire automotive industry has embraced quality tools, such as concurrent engineering, continuous improvement, and statistical process control but the main difficulty lies in determining what quality practices are the most likely to improve quality and overall firm performance. This work presents the hands-on 
experience of quality tools use and implementation at each PRP stage within a toplevel supplier company in the automotive industry. The objective of this study is to explore the strategic implications of quality tools adoption with the aim of building theory. Because the focus of this research is exploratory, the authors qualitative data collection methods, primarily field-based collection- to help ensure that important variables and relationships were identified.

\section{Quality management frameworks and standards}

Producing with "quality" is the philosophy of any company in this industry. It has an extensive experience in quality management and this materializes in the form of quality assurance standards that have arisen throughout the years, such as QS, TS, VDA, EAQF, AVSQ, etc. Nowadays it has its own specifications, such as the ISO/TS 16949 standard, based on the ISO 9001 model, with specific requirements of the automotive industry, raising the level of requirements and quality of this standard.

\subsection{Quality standards development}

The automotive industry began its activity in the $17^{\text {th }}$ Century, using steam as propulsion element. After significant progress in gas-powered engine design, the first petrol engines emerged in 1889 . In the early $20^{\text {th }}$ Century, mass production of automobiles begins in the USA, being leaders in automobile manufacturing. Some years later, European manufacturers learnt the lessons and built manufacturing plants in the UK, France, Germany and Italy.

In the WWI and WWII period, most automobile manufacturing countries drastically reduced their activity. In 1939, General Motors (mainly) and Ford were the leading company in the US market, Opel and Mercedes-Benz in Germany, Renault, Peugeot and Citroën in France, and Morris, Ford, Vauxhall (of General Motors), Standard and Rootes (Jaguar, Rover and Rolls-Royce makes) in the United Kingdom. Car production outside the USA survived mainly because General Motors, Ford and Chrysler established manufacturing plants in other countries. After the war (1945), there was a significant expansion of automotive sector. Large automobile mergers took place to be more competitiveness among manufacturers.

Japanese car industry arose in the sixties, with a more competitive and aggressive philosophy of work, based on quality principles. American manufacturers decide to change their management strategy and form, and military quality standards are adopted. Already in 1988, their supplies are requested specific requirements. Each manufacturer has a manual containing his own requirements and suppliers have to make an effort to fulfill them; this issue gets complicated when suppliers work for several manufacturers at the same time. Aware of this working method not being competitive, the Big Three U.S. automakers (Chrysler, Ford \& General Motors, 1994) organize a working group whose aim is to unify their different requirement manuals. This working group efforts became reality in 1994 with the publication of QS-9000-Quality System Requirements standard, that derives from the 1994 version of ISO 9000 (Kartha, 2004; Bandyopadhyay, 2005). Later, other American manufacturers of the industry accepted this standard as well. 
The German automotive sector reconsidered this issue because of the increased competence, the aim of being more competitive, costs reduction, etc.. This is how the "Verband der Deutschen Automobilindustrie"(VDA) arose in Germany; this organism makes the VDA 6 Qualitätsstandard der deutschen Automobilindustrie standard; its core part is VDA 6.1 (1996) whose target is to allow for assessment under comparable conditions of different quality management systems. Similarly to the regulations that came into being in the USA and Germany, two more standards also sprang up: the Evaluation Aptitude Quality Supplier (FLAA) in France (1994), quality system standards for Citroën, Peugeot and Renault, with regard to their suppliers and the Association of Quality System Evaluators (AVSQ) (1995) in Italy.

Lately, the automotive industry (like the rest of sectors), follow the globalization tendency. Not only the main automobile manufacturers, but also their suppliers apply alliance and fusion policies, thus, there is a need for harmonizing the different regulations on quality management that had arisen in the automotive industry. The latest result of this globalization effort is the UNE-ISO/TS 16949 standard, which replaces the QS 9000 standard.

The first edition of this technical specification (year 1999) was mainly based on the ISO 9000:1994 standard. In 2002, there was a second edition (UNE-ISO/TS 16949:2002) based on ISO 9001:2000. The current version of the specification is ISO/TS 16949:2009 (2009). The IATF (International Automotive Task Force) was established to create this standard. The main automotive manufacturers participated in this working group together with national organizations like VDA and some members of ISO TC 176 (technical committee of the ISO organization for qualityrelated regulations). Its quality references are shown in Fig. 2.

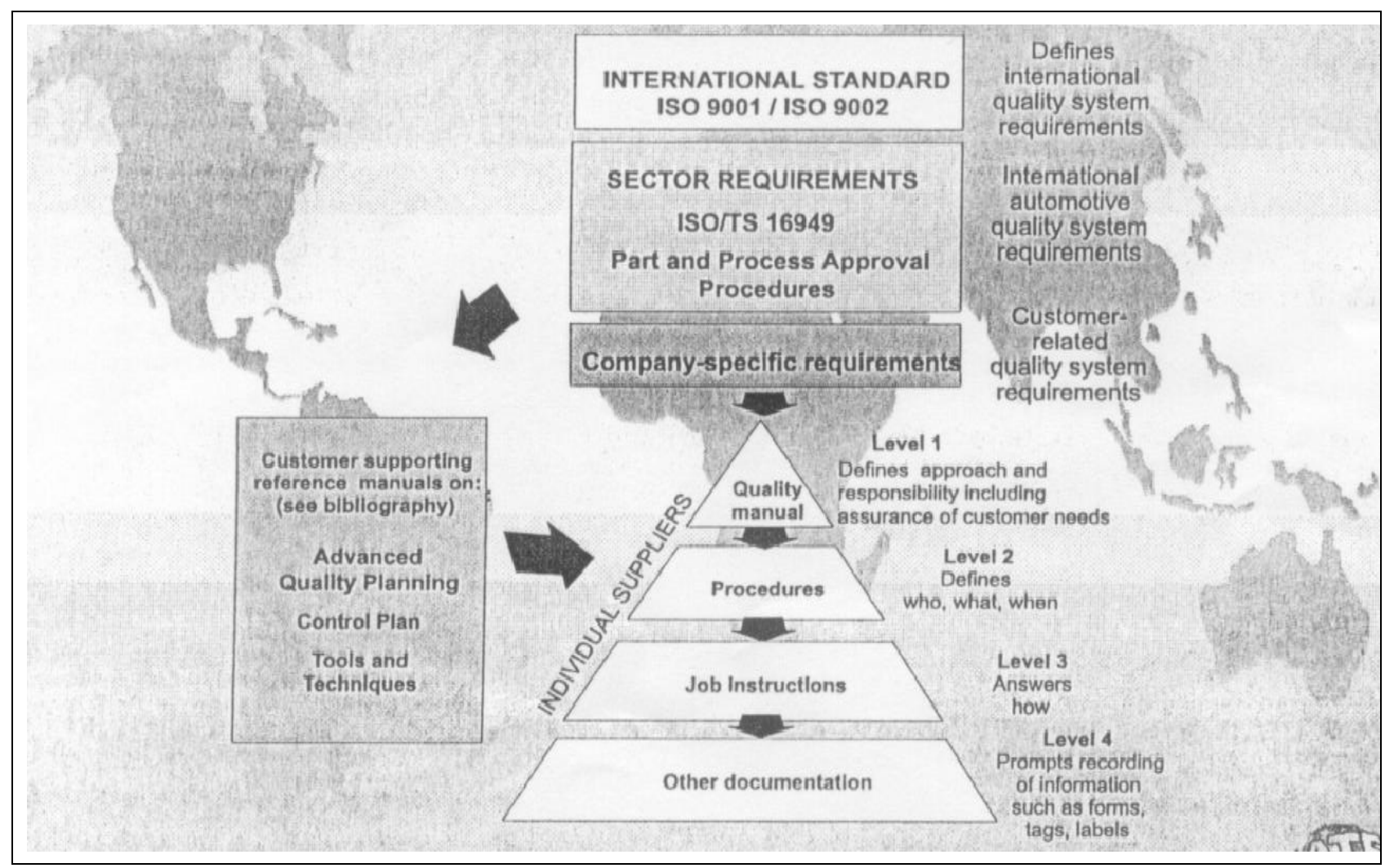

Fig. 2. Quality references for the sector's suppliers according to the IATF (source: http://www.aiag.org) 
General Motors and Ford insisted on all its suppliers making the transition from QS 9000 to ISO/TS 16949 before the end of 2006, whereas Chrysler requested such transition in 2004. About 6,000 first and second-level suppliers around the world have obtained the ISO/TS 16949 certification. American companies are on top of the list, followed by German, French, Spanish, Italian, Chinese, Brazilian and Indian firms (Davis, 2004).

\subsection{Quality Management}

The ISO/TS 16949 international standard establishes the particular requirements of the implementation of ISO 9001:2000 in the automobile production. This is a useful framework to understand the quality planning of the product in general, the PRP, being one of the most important parts of the standard. Broadening the project management concept, this standard requires the establishment of a method so that the PRP is measured up by means of specific milestones, including the corresponding management analysis and revision. Factors to be accounted for include quality, risks, costs and deadlines.

Based on its working method, numerous companies of other sectors have taken this model of management and have tried to apply it and adapt it to them. It is because of this that quality management implementation in the best possible conditions requires the support of some techniques that contribute to their development.

While some of these tools can be used to reveal problems with the staff participation, others can be drawn from measurements or data obtained from the process to be controlled and, after analyzing such data, the intended results are obtained. In some occasions, these results are used to control the process: if the results are within the limits established for each process, the process is controlled; otherwise, corrective measures will be needed to be applied to it. Some other times, the only interest is to see the results of a process with a graphical representation. In general, there is a wide number of ways (some of them complex) to control a process, to find failures, to improve systems, to analyze risks, etc.

The automotive sector is managed by the Major Automobile Manufacturers (MAM), like Ford, General Motors, Volkswagen,... Their working method or Project management follows specific phases: offer, contract revision, product design, product design validation with prototypes, industrialization, product validation and process, and finally production optimization. MAM have Design Centres and Production Facilities around the world.

Development projects of new vehicles take place at Design Centres; such projects have an average 3-year planning for new vehicles and 1 or 1.5-year for vehicle re-styling. Each vehicle component is perfectly designed in this Development Projects: geometry, functionality, technical characteristics, as well as the interrelation and interferences among them. Each component characteristics and determining factors are recorded in the Specification (tender documentation), where drawings, regulations, tests to be undertaken, etc. are specified. 
Many times at this design stage, MAM's include some suppliers in their working team because of their knowhow (experience), that this way participate in the vehicle design. They are known as Development Providers. In the Production Facilities, MAM only assemble components. An intermediate stage between design and production is therefore necessary in the Project.

That stage is the suppliers' allocation, which determines which suppliers are responsible for the mass supply of the different components to production plants. The so-called Buyer Leader is in charge of suppliers' allocation. The allocation is performed on the basis of different criteria: economic (offer), experience, quality incidents in other supplies,...

Control and follow-up on suppliers (that reach up to mass supply of allocated components) by the Manufacturer are critical at this stage. Considering the amount of components, several Quality Supplier Engineers are appointed. They are responsible for controlling that the supplier fulfills some milestones, such as the delivery of prototypes to the Manufacturer (they are non-representative samples but show the supplier's capacity to make parts; at this point the supplier does not have the final manufacturing resources) and the deliveries of initial samples (representative pieces of production that have all the necessary working resources, prepared workstation, documents, ...).

The Quality Supplier Engineer appointed, carries out a Pre-Production audit (Run at Rate), in which the Auditor checks that the Supplier can provide good parts and complies with the frequency requested by the Manufacturer. In order to do this, work stations are analyzed, together with all documents regarding both product and process quality.

The manufacturer work is based on solid management skills of new vehicle design project and a subsequent good logistics management; since the Production facilities assemble components "just in time", provided by a great variety of suppliers, with almost zero stocks. Those suppliers that provide their products directly to the "Production facilities" are called Tier 1 suppliers. Those who supply parts to the latter are the Tier 2 suppliers, and so on and so forth: Tier 3 , Tier 4 suppliers... In order to achieve this type of category, supply capacity and quality is needed to be shown first; therefore, there are some steps or stages throughout the Project that all suppliers in the automotive industry must follow in order to fulfill the supply requirements or adequate levels. All these stages are reflected in a document called "Product Quality Assurance Dossier" or "Production Part Approval Process"; such document includes all quality requirements and stages to be complied with at this stage of development of the supplier until mass production.

Because of what has been set out, it can be concluded that project management in the automotive sector is characterized by the stages shown in Fig 3. At each of these stages, it is essential and imperative that a range of quality tools are adopted as working method. All these tools are mainly based on the philosophy of zero defects and continuous improvement. 


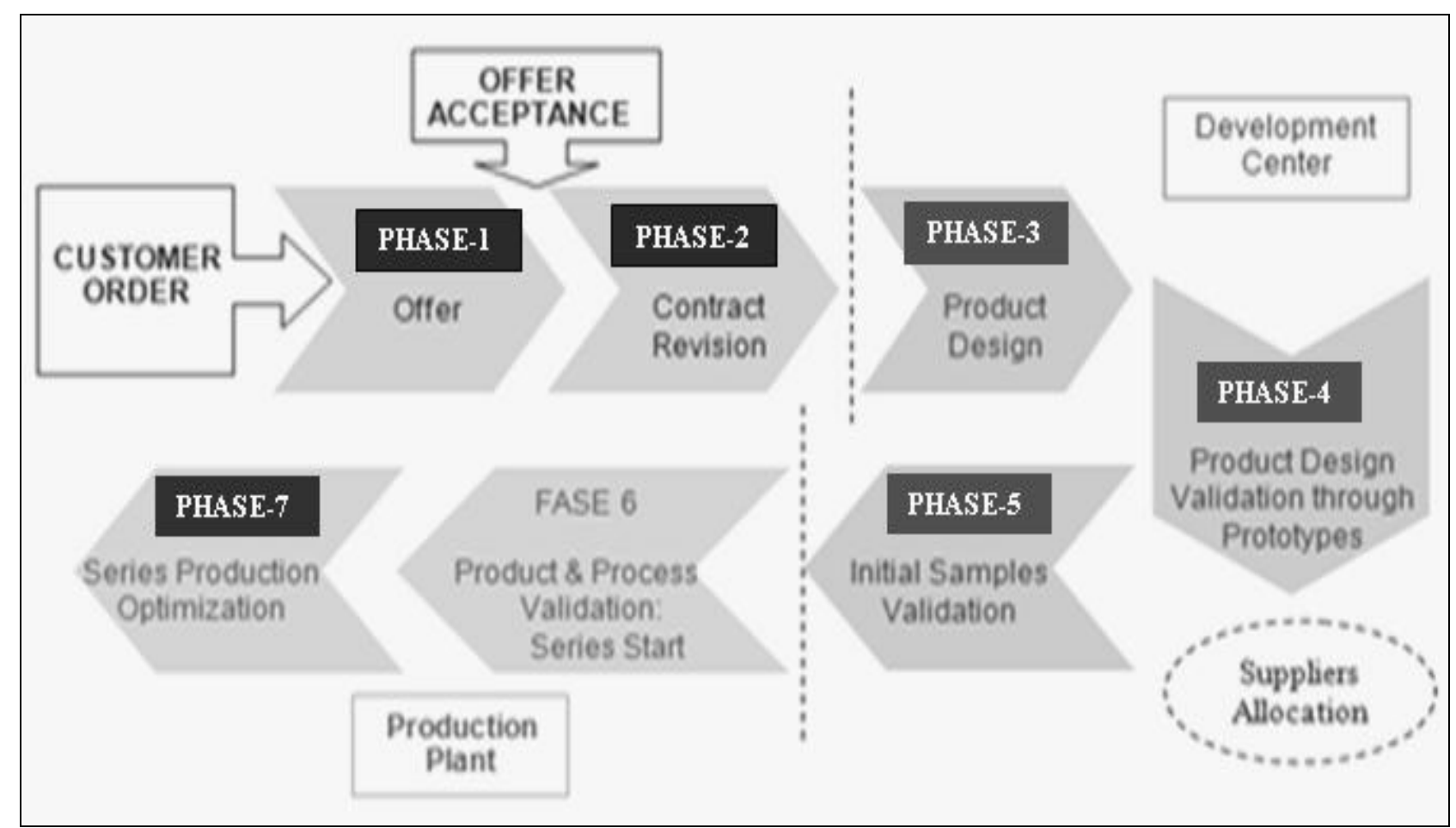

Fig. 3. Project stages in the automotive sector

\section{Examination and clasification of the quality tools}

This report focuses on the most used tools in the sector and on those forced to be used by the manufacturer as a general rule:

1. PDCA cycle or Deming

2. Q7: the seven basic tools of quality

3. M7: the new seven tools

4. Planning techniques

5. Control techniques

6. Improvement techniques

\section{The DEMING or PDCA cycle}

The PDCA cycle, is used as a work philosophy and is the core principle of ISO TS. This methodology is inherent to the sector on a daily basis and it sets the steps to be followed to undertake any improvement (Fig. 4).

- PLAN: Assortment of problems and planning of improvement actions $\rightarrow$ To know the problem that is tried to be improved, to look for the root reason, solutions to this reason,... Here, analytical tools like Q7 are used.

- DO: Realization of concrete actions to solve the problem $\rightarrow$ To put the necessary means for improvement.

- CHECK: Validation of results and controlling of aims $\rightarrow$ To measure the obtained results, to see if the aims are reached ...

- ACT: Improvement of actions, of the situation, etc. $\rightarrow$ To extend the solutions to other similar problems, families of pieces... 


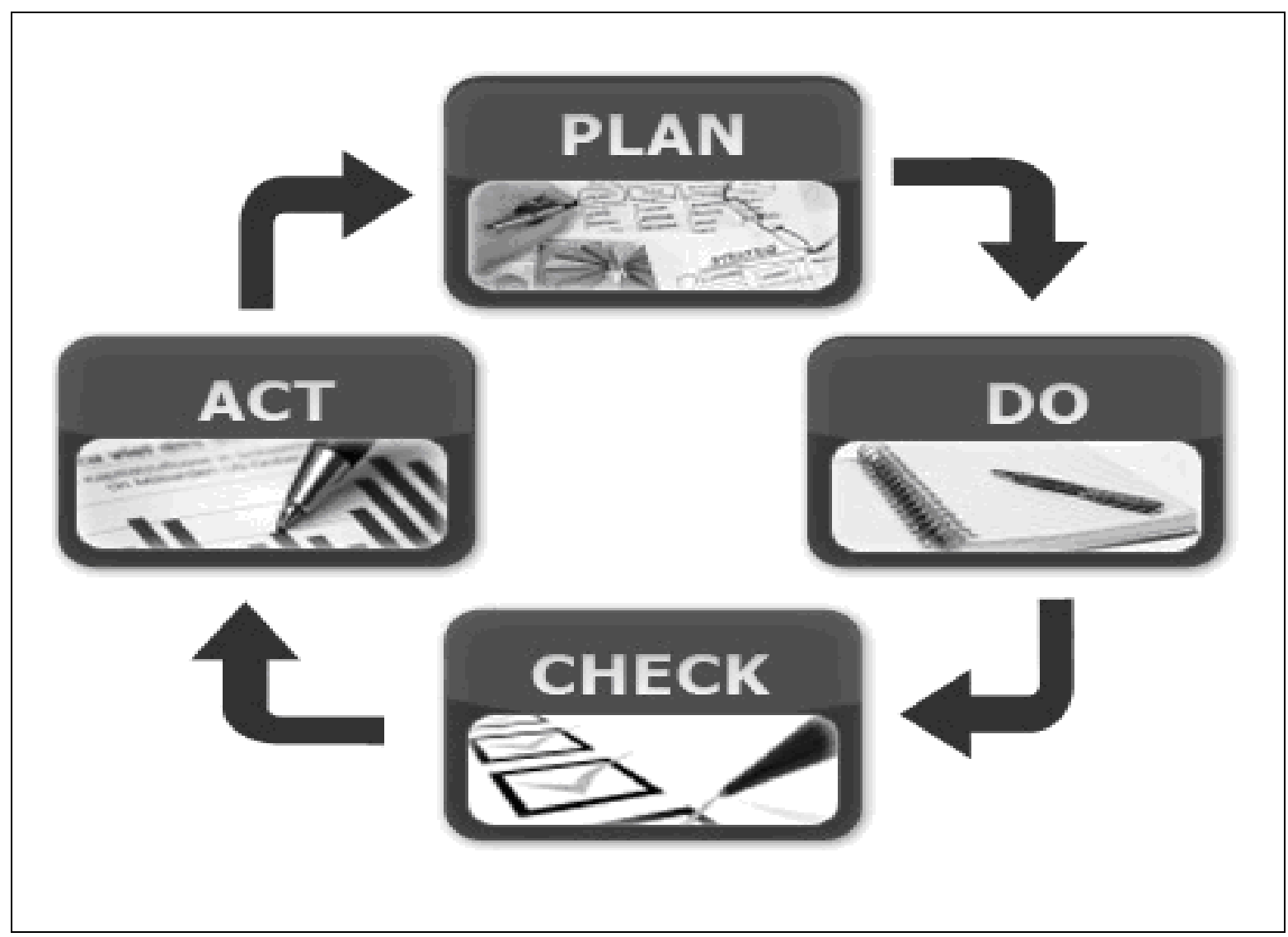

Fig. 4. Deming cycle

It is based on the principle of quality management continuous improvement, one of the basis supporting the quality philosophy. It analyzes existing data and focuses on historical process capability to know the problem, that is to say, on obvious and quantified facts and problems.

\section{Q7: The seven basic tools of quality}

They are known by "The Seven Basic Statistical Tools" because they are appropriate for people with little formal education in statistics (Ishikawa, 1985):

- Check sheet

- Flow charts

- Cause-and-Effect Diagrams (fishbone)

- Control Charts

- Histograms

- Pareto Charts

- Scatter Plot

A right approach to deal with issues is to see first if the issue exists by using verified data (check sheet), quantifying its severity (Jiménez, 2010), if it is repetitive and representative (histograms, Pareto charts) and using tools like cause and effect diagrams intending to determine the root reason of the problem. Specifically, and as an example, the scatter plot was used to pursue a test correlative to the hardness and fatigue test applicable to polyurethane seats of any vehicle; such test is usually 
performed 36 hours after their production. A test correlative to the previous one was found; it was totally significant, but carried out 6 hours before its production, with the objective of knowing beforehand if the production carried out is correct or, if that new test provides incorrect results, being able to tackle the problem in production before the 36 hours where the problem would be encountered with the standard test.

\section{M7: The new seven tools}

This is an assortment of useful tools for decision-taking at management level (Barker, 1989). They are not new, but their popularity has increased in the engineering and manufacturing fields over the last twenty years (Omar \& Kleiner, 1997). They are planning and management tools aimed at Management:

- Affinity Diagram

- Relations Diagram

- Tree Diagram

- Matrix Data Analysis

- Matrix Diagram

- Process Decision Program Chart (PDPC)

- Arrow Diagram

\section{Planning techniques}

These tools are aimed at preventing the manufacturing of defective parts (Rodríguez, 2011). They are applied to plan the manufacturing process, manufacturing tools, control frequency, personnel carrying out controls:

- Benchmarking: competence analysis; it is a systematic, continuous measurement and comparison process to determine "best" practices in order to improve an organization's performance (Watts, 2012).

- QFD (Quality Function Deployment): The core of this approach is a chart called house of quality. This technique identifies customer requirements and provides a discipline to ensure that those requirements are included in product design and in planning process. It reduces product development cycles, increasing quality and reducing costs (Chan \& Wu, 2002).

- Capability Studies. They are is used to know if manufacturing processes are stable and capable. This tool is closely related to statistical process control.

- DOE (Design of Experiments): method used for process optimization. Its implementation implies a reduction in the number of tests, so product development can be organized more economically (Montgomery, 2004).

- FMEA (Failure Mode and Effects Analysis): systematized preventive method intended to identify and evaluate the potential failure of a product/process and its effects, as well as to determine actions which could reduce the chance of the potential failure occurring (Carlson, 2012). It is a compulsory tool in the automotive industry to be aware of the different failures that can arise at every moment; the aim is to account for three aspects: seriousness of the failure, failure occurrence or likeliness of occurrence, and failure detection or identification 
ability during the process. Once those aspects are valued, the criticality rating is estimated as the multiplication of the three. If that value is higher than that requested by the Manufacturer, actions are taken. Since the seriousness of the failure cannot be changed, focus must be on occurrence or detection, in order to diminish the criticality rating. The ideal thing is to deal with occurrence, by means of elements called pokayokes or "mistake proofing" systems that avoid mistakes made by human error. Some other times, it is not possible to focus on occurrence, and prevention is then tackled, seeking systems that fully detect failures before moving to the next stage. As far as costs are concerned, it is important to detect failures at the beginning of processes and not at the end of manufacturing.

Control plan: document used to plan all controls to be carried out in a manufacturing process, per job, as a result of the FMEA planning. They are mandatory in the automotive sector.

\section{Control techniques}

The following quality techniques are widely used as control techniques:

- SPC (Statistical Process Control): in every production process, it is necessary to know up to which extent the products meet the pre-established requirements (Automotive Industry Action Group, 1995). The Voice of the Process (variability observed), and the "Voice of the Customer" (Specification limits) have to be compared. Therefore, Capability Studies provide indicators called capability indices ( $\mathrm{Cp}, \mathrm{Cpk}, \mathrm{Pp}$, Ppk), that inform about the level of compliance. On the other hand, process stability is to be guaranteed in order to tackle them if they are out of control. Control charts represent the Statistical Process Control (SPC) tool and notices when a process stops following the random pattern of normal behaviour.

- Audits: there are many types of audits, classified by internal or made by the customer. They are daily present in automotive companies, where there are several auditors that plan audits of all kinds yearly: Production, Pre-production (Internal); Run at Rate (Pre-production Customer); Quality; Product; Spic \& Span (5-S philosophy); Security and Regulations.

- Definition of indicators: Key Performance Indicators are quantifiable aspects that reflect the critical factors. There are many important indicators related to quality. They are defined during the different Project development stages, like control tool, for example "quality incident indicators of suppliers", of compliance of initial samples and prototypes, those referred to delays in deliveries, suppliers' quality systems... The main goal is to find proper indicators for particular processes and find methodology that helps to identify those indicators (Nagyova \& Pacaiova, 2009). 


\section{Techniques for improvement}

Finally, the quality tools used as techniques for improvement are the following:

- Continuous improvement

- TPM: Total Productive Management

- Lean Six Sigma: methodology that firms can use to improve the output quality of a process

- Poka Yoke: "mistake proofing" system that helps to prevent human errors.

- Improvement group. Collaborative working method between several production workers, where there is a critical figure: the improvement group facilitator (usually a quality-related person), that guides the group as regards some steps to be followed to solve a problem. That person also provides workers with knowledge and orientation on the use of quality tools.

- 8D Tool (8 Disciplines): it is a method used to resolve customer-related problems; customers are required to use them. The eight disciplines are followed for problem solving. The disciplines comprise several data-collection tools, determine root cause, ...

Among them, the most used are the Pokayokes, improvement groups as teamworking method for problem-solving (Mari-García, 2009) and the 8D tool to resolve customer-related incidents.

\section{Research Methodology and Results}

In order to analyze the most suitable tools and to fit them in the different stages of the project, the idea of some follow-up project monitoring surveys came up, aimed both at the Project Manager and the Project Quality Manager. The stages of the Project relative to the offer and contract (Fig. 3) have been excluded from the study, therefore the stages considered in the surveys are the 5 remaining.

Surveys took place in two types of companies: Tier 1 suppliers that manufactured totally different products: seats and pipes, in order to ensure that product type does not influence the chosen type of quality tool. Seventeen Projects ended in 2011 were analyzed at each company; specifically, they were 10 projects of one company and 7 of another. A structured interview protocol at all site visits were used. The protocol covered a number of topics relating to different quality tool: if they were used, which were the most popular, at which stages, which were the most successful, which were verified not to be useful, etc.

Qualitative theory building research is an iterative process so the data collection and data analysis should be done simultaneously: the data from one case is collected and then analyzed before the next replication is performed. If needed, any improvements in the protocol for subsequent replications. This ability to refine and improve upon the protocol between cases is a significant advantage to this type of research. 
Choosing each tool for each stage depends both on the experience and on the intuition of each interviewed person, so the method used to validate the survey was the descriptive statistics with the SPSS v. 18 program and correlative analyses to identify each project stages with each tool.

Limitations of this study include generalizability, causality, and empirical testing. The limited sample size and the industry involved constrains the generalizability of the findings.

Some other surveys regarding Projects that began in 2011 have been initiated ( 3 in one company and 4 in another). Today, we already have results for the Project design stages, and these data have been included to analyze and reinforce the quality tools used at the first stage of design.

After the experience and implementation of such tools (previously summed up) in a Tier 1 supply company of the automotive industry, it has been proven that the best tools to be applied at each of the different stages of the Project are those included in Table 1.

\begin{tabular}{|l|l|}
\hline PROJECT STAGES & QUALITY TOOLS USED \\
\hline Stage 3: Quality in design & $\begin{array}{l}\text { - FMEA } \\
\text { - Control Plan }\end{array}$ \\
\hline Stage 4: Quality in prototype s & - PPAP.Control Plan \\
\hline Stage: Quality in initial samples & $\begin{array}{l}\text { - Pokayokes Design } \\
\text { - Control Plan }\end{array}$ \\
\hline & $\begin{array}{l}\text { - Pre-production audits. Run at Rate. } \\
\text { - Control Plan }\end{array}$ \\
Stage: Quality at series beginning & - Design of quality indicators as \\
& management tool \\
\hline \multirow{3}{*}{ Stage: Quality in series } & - Customer claim follow-up. 8 D Tool \\
& - Quality incident indicators of suppliers", \\
& - SPC. Control Plan \\
\hline
\end{tabular}

Tab. 1. Structural Theory and Industrial Structures

Suggestions for future research focus on the need for a quantitative assessment of relationships identified from this study.

\section{Conclusions}

In today globalized world, there is a growing need for tools that make it possible to measure up the quality processes used by each of them, since the manufacturers of final products are committed with users to provide quality products, putting the company's prestige at risk. Because of this reason, having quality 
guarantees of the materials and components provided by suppliers can determine the success or failure of a product, or even of a company.

Considering this situation, the idea of developing a global standard at the different project stages arose; it would allow companies to determine the quality that they could offer on real grounds. The goal is to be able to define a standard to be followed by the companies of the sector, either because of the good results of its implementation or because of its compulsory nature regarding automotive quality regulations.

\section{References}

Automotive Industry Action Group, Chrysler Corporation, Ford Motor Company, General Motors Corporation (1995). Statistical process control (SPC): reference manual. Automotive Industry Action Group

AVSQ '94 ANFIA Valutazione Sistemi Qualità (1995). Edizone 3 plus Addendum QS 9000 all AVSQ, edizione Marzo 1997

Bandyopadhyay, J.K. (2005). The global supply chain assurance practices of United States automakers: a survey. International Journal of Management, Vol. 22, No. 4, 582-694

Barker, R.L. (1989). The seven new QC tools. Proceedings of the First Conference on TQM Tools and Techniques. IFS Publications, 95-120

Besterfield, D., Besterfield-Michna, C., Besterfield, G. (2003). Total Quality Management (3rd edition), Prentice-Hall, ISBN 9780130993069, New Jersey

Carlson, C. S. (2012). Effective FMEAs: Achieving Safe, Reliable, and Economical Products and Processes using Failure Mode and Effects Analysis. John Wiley \& Sons, Hoboken, ISBN 9781118312568 , New Jersey

Chan, L., Wu, M. (2002). Quality function deployment: A literature review. European Journal of Operational Research, Vol. 143, No.3, 463-497, ISSN: 0377-2217

Chrysler Corporation, Ford Motor Company and General Motors (1994). Quality System Requirements QS-9000 1st Edition, AIAG (810) 358-3003

Comité de automoción (2004). Herramientas para la calidad. AEC, Asociación española de la calidad

Dale, B., Van der Wiele, T. \& Van Iwaarden, J. (2007). Managing Quality (5th Edition), Blackwell Publishers, ISBN 9781405142793

Davis, B. (2004). One Standard fits all. Professional Engineering, Vol. 17, No. 9, 4345

EAQF '94 Evaluation aptitude Qualité Fournisseur (1994). Edition plus QS-9000 appendix to EAQF March 1997 edition

Greene, R. (1993). Global quality: a synthesis of the world's best management methods. ASQC Quality Press, ISBN 9781556239151, Milwaukee, USA

Ishikawa, K. (1985). What is Total Quality Control? The Japanese way, Prentice Hall, ISBN 9780139524332, New Jersey, USA 
ISO/TS 16949:2009 (2009). Quality management systems: Particular requirements for the application of ISO 9001:2008 for automotive production and relevant service part organizations. ISO 9000, Quality Management Systems, ISO Website

Jiménez, J.M. (2008). El coste de la variabilidad de los procesos. Proceedings of the XIII Congreso de Calidad y medioambiente en la Automoción.

Jiménez, J.M. (2010). El valor de los datos. Proceedings of the XV Congreso de Calidad y medioambiente en la Automoción

Juran, J. \& Gryna, F. (1998). Juran's Quality Handbook, McGraw-Hill, ISBN 9780139524332

Kartha, C.P. (2004). A comparison of ISO 9000:2000 quality system standards, QS 9000, ISO/TS 16949 and Baldrige criteria. The TQM Magazine, Vol. 16, No. 5, 331 - 340, ISSN 0954-478X

Mari-Garcia, J. (2009). La gestión de los recursos humanos: gestión del talento en el sector de automoción. Jornada sobre innovación y mejora de procesos en el sector de automoción

Montgomery, D.C. (2004). Design and Analysis of Experiments (6th edition), John Wiley \& Sons.Inc, ISBN 9780471487357

Nagyova, A. \& Pacaiova, H. (2009). How to Build Manual for Key Performance Indicators -KPI, Chapter 15 in DAAAM International Scientific Book 2009, pp. 135-142, B. Katalinic (ED.), published by DAAAM International, ISBN 978-3-901509-69-8, ISSN 1726-9687, Vienna, Austria

Nagyova, A. \& Pacaiova, H. (2010). Quality Evaluation Methodologhy for Research projects, Chapter 22 in DAAAM International Scientific Book 2010, pp. 219226, B. Katalinic (ED.), published by DAAAM International, ISBN 978-3901509-74-2, ISSN 1726-9687, Vienna, Austria

Omar, T.A. \& Kleiner, B.H. (1997). Effective decision making in the defence industry. Aircraft Engineering and Aerospace Technology, Vol. 69, No. 2, 151-159, ISSN: 0002-2667

Rodriguez, E. (2011). Diseño robusto. La calidad preventiva desde el diseño y el desarrollo. Qalidad, No. I , 49-52, ISSN 156-4915.

VDA 6.1 Qualitätsmanagement in der Automobilindustrie (1996). QM Systemaudit 3 vollständig überarbeitete Auflage 1996/1

Watts, F.B. (2012). Engineering Documentation Control Handbook .Configuration Management and Product Lifecycle Management (Fourth Edition). Chapter 15, 335-346, Elsevier, ISBN 9781455778607, United States 